числе, с лабораториями при РАН, достигаются и цели приобретения умений и навыков с обращением современного химического, биологического оборудования.

$$
* * *
$$

1. .М. Саркисян, Д.А. Земляной, В.Г. Пузырев. Актуальны вопросы преподавания химии и гигиены иностранным студентам в Санкт-Петербургском государственном педиатрическом медицинском университете. В сборнике региональной межвузовской учебно-методической конференции с международным учатием «Инновации в образовании», посвященной 100-летию ФГБОУ ВО КубГМУ Минздрава России. 2020 г. с 367-370.

2. 3.М. Саркисян, И.В. Шкутина, А.В. Кабанов. Актуальные научные проекты студентов в рамках студенченческого научного общества Санкт-Петербургского педиатрического университета. В сборнике региональной межвузовской учебно-методической конференции с международным учатием «Инновации в образовании», посвященной 100-летию ФГБОУ ВО КубГМУ Минздрава России. 2020 г. с. $370-373$.

\title{
Чернякова Н.С.
}

К вопросу о роли учителя в достижении метапредметных результатов младших школьников средствами проектной деятельности в контексте ФГОС

ГОУ ДПО Тульской области «Институт повымения квалификации и профессиональной переподготовки работников образования Тульской области»

(Россия, Тула)

doi: $10.18411 /$ sr-10-04-2020-05

idsp: sciencerussia-10-04-2020-05

\section{Аннотация}

Важнейшим требованием федеральных государственных образовательных стандартов начального общего образования является организация проектной и учебноисследовательской деятельности. В данной статье рассматриваются вопросы использования метода проектного обучения в современной практике учителя для достижения младшими школьниками метапредметных результатов.

Ключевые слова: метапредметные результаты, учебная деятельность, метод проектов, учебные проекты, педагогическое руководство.

\section{Abstract}

The most important requirement of federal state educational standards of primary general education is the organization of design and educational research activities. This article discusses the use of the project-based learning method in modern teacher practice to achieve meta-subject results by younger students.

Keywords: meta-subject results, educational activities, project method, educational projects, pedagogical guidance.

Современное понимание качества образования связывается с достижением метапредметных результатов, необходимых каждому человеку для самоопределения и самореализации себя как личности. Понятие «метапредметные результаты обучения» введены в практику работы школы нормативным документом - ФГОС начального общего образования. Именно эти результаты выступают как принципиально новые в теории и практике обучения. Качество образования зависит не от объёма фактического материала, а от овладения обучающимися ключевыми компетенциями, которые должны проявляться в реальной ситуации. Новые образовательные технологии предлагают инновационные модели построения такого учебного процесса, где на первый план выдвигается взаимосвязанная деятельность учителя и ученика, нацеленная на решение как учебной, так и практически значимой задачи. 
В соответствии с таким подходом роль учителя в образовательном процессе возрастает. Педагог создаёт условия для формирования личности ученика в учебной деятельности; вовлекает каждого учащегося в активную познавательную деятельность; организует учебные ситуации, в которых ученик может пробовать свои силы для решения возникающих учебных проблем; помогает их решить совместными усилиями; планирует совместную работу в сотрудничестве при решении разнообразных учебных задач; знакомит с путями получения необходимой информации с целью формирования собственного аргументированного мнения по той или иной проблеме, возможности её всестороннего исследования [6, с. 173].

Методом, реализующим компетентностное образование, всё чаще рассматривается метод проектов. Главная идея метода основана на деятельностном подходе, и изначально предполагалось использование окружающей жизни как лаборатории, в которой и происходит процесс познания [2, с. 272].

Основная ценность метода проектов состоит в том, что он ориентирует учеников не на простое изучение темы, а на создание конкретного образовательного продукта [4, c. 466].

Проект - это самостоятельная исследовательская работа, предполагающая развитие аналитического, ассоциативного и логического мышления в процессе анализа и синтеза фактов и явлений, в процессе установления интегративных и логических связей. Обучающиеся, исследуя проблему, устанавливают причинно-следственные связи, овладевают знаниями из различных областей. Данная технология также позволяет развить речевые умения (говорение, аудирование, чтение, письмо), совершенствует умение работать с текстами разных стилей в процессе поиска информации.

Задачи, которые ставит проект, разнообразны: от возможности самому обучающемуся выбрать тему до понимания важности работы в сообществе, а задача педагога - научить его находить информацию самостоятельно, определить свою позицию.

В ходе подготовки проекта участники образовательного процесса ставят задачи.

Учитель - создать условия для формирования: положительной мотивации к учебной деятельности и учебному материалу на основе интереса; умения искать и выделять необходимую информацию в тексте, работать с различными источниками информации; коммуникативных навыков; умения строить монологическое высказывание в публичном выступлении.

Ученик - повысить самооценку; получить навыки самостоятельной работы с источниками информации; приобрести коммуникативные навыки; получить умения презентовать себя и свою работу, возможность самореализации.

Отметим, что в современной педагогической науке разработаны различные классификации учебных проектов. Опираясь на научные исследования Г. М. Коджаспировой [1, с. 96], назовём критерии отбора, виды учебных проектов и их классификационные характеристики.

Так, например:

1. Приняв за основу преобладающий вид деятельности учащихся, выделяют следующие виды проектов:

- информационный (сбор и обработка информации по анализируемому вопросу с целью её представления в дальнейшем различной аудитории);

- практико-ориентированный проект (рекомендации по решению различных вопросов);

- исследовательский проект (исследование проблемы, учитывая все требования к проведению научного исследования); 
- творческий проект (проявление творческого подхода, авторской позиции в решении проблемы);

- ролевой проект (разнообразные виды исторических, литературных, деловых, операционных ролевых игр).

2. Учитывая комплексность и характер контактов, учебные проекты подразделяются на монопроектные и межпредметные проекты.

3. Опираясь только на характер контактов, учебные проекты можно представить как: внутриклассные, внутришкольные, региональные, международные.

4. Учитывая время учебного проекта, их можно сгруппировать в виде: минипроектов, краткосрочных, недельных, долгосрочных (годичных) проектов.

5. По составу участников учебные проекты могут быть: персональными (индивидуальными) или групповыми.

Практика проведения проектов с младшими школьниками может рассматриваться как особое направление внеклассной или внешкольной работы, тесно связанное с основным учебным процессом и ориентированное на развитие исследовательской, творческой активности детей, а также на углубление и закрепление имеющихся у них знаний, умений и навыков. Эта работа может иметь и локальный, и фронтальный характер, ее можно проводить индивидуально, с небольшой группой детей в процессе основных учебных занятий.

Bсе темы, предлагаемые в качестве проектных, должны быть посильны пониманию ребенка. Чем меньше ребенок - тем проще проект, поэтому проекты в начальной школе отличаются несложностью, простотой. Ученик должен отчетливо представлять не только задачу, стоящую перед ним, но и пути ее решения, уметь составлять план работы по проекту (на первых порах, конечно, при помощи учителя). Важно, чтобы выбору проекта предшествовала «вспышка интереса» как побуждающее событие, заинтересованность в проекте.

Виды проектов: проекты-наблюдения; проект-рассказ; конструктивные проекты; экскурсионные проекты.

Проектные задания, предложенные на выбор учителем, должны обязательно предусматривать использование школьниками хорошо знакомых им знаний в сочетании с новыми - теми, что предстоит приобрести. Знакомое создает чувство уверенности в своих силах, а неизвестное ведет вперед, к новым знаниям. Профессионализм учителя выражается в том, насколько уверенно может он спланировать работу учащихся над проектом, обеспечить мотивацию к труду, чтобы задание находилось в зоне ближайшего развития каждого ученика. Роль педагога состоит в том, чтобы уметь контролировать лишь ключевые этапы выполнения проекта, работая по методу убывающих подсказок.

Приняв за основу исследования Шамовой Т.И., Третьякова П.И., Капустина Н.П. можно определить стадии разработки учебного проекта [5, с. 194-195]. Это:

- разработка проектного задания, включающая в себя: выбор темы проекта, выявление подтем в теме проекта, формирование творческих групп, отбор литературы, формулирование заданий, вопросов для групп, определение форм выражения итогов проектной деятельности;

- разработка проекта;

- презентация;

— рефлексия.

Среди выше обозначенных стадий разработки учебного проекта особое значение принадлежит общественной презентации и рефлексии. При проведении презентации учитель проводит экспертизу разработанного проекта, привлекая для этого процесса учащихся из других классов, родителей, представителей от общественных организаций. В то же время деятельность учеников связана с сообщением результатов выполненной 
работы - презентации учебных проектов. Процесс рефлексии предполагает с одной стороны оценку учителем педагогического руководства деятельностью младших школьников, а с другой - самооценку учащимися полученных результатов, оценивание собственного участия в проекте, учитывая оценки других. «Критерии оценки проекта должны быть понятны и доступны участникам проекта, их должно быть не более 7-10, известны с самого начала работы над проектом. Оцениваться, прежде всего, должно качество работы в целом, а не только презентация» [1, с. 97].

Таким образом, технология проектного обучения « ... - это преимущественно самостоятельная или в малой группе деятельность ученика, направленная на решение значимой для него задачи (проблемы), осуществляемая в режиме поиска, протекающего в проживаемой учеником имитированной или реальной действительности проектной деятельности» [5, с. 197]. Главным критерием оценки выполненного проекта является достижение целей проекта, его надпредметных целей, связанных с развитием творческих познавательных способностей учащихся начальных классов, их самостоятельности в познавательной деятельности. Метод проектного обучения призван дать новое направление всему процессу обучения в начальной школе, что в целом выведет его на новый качественный уровень, имеющий целью создание условий для достижения младшими школьниками метапредметных результатов.

$$
* * *
$$

1. Коджаспирова Г.М. Педагогика в схемах, таблицах и опорных конспектах. - М.: Айрис - Пресс, 2008. $-256 \mathrm{c}$.

2. Обучение русскому языку в школе: учеб. пособие для студ. пед. вузов/ Е. А. Быстрова и др.; Под ред. Е. А. Быстровой. - М.: Дрофа, 2004. - 240 с.

3. Поливанова К. Н. Проектная деятельность школьников: пособие для учителя / К. Н. Поливанова. М.: Просвещение, 2008. - 192 с.

4. Хуторской А. В. Практикум по дидактике и современным методикам обучения [Текст] / А. В. Хуторской. - СПб.: Питер, 2004. - 541 с.

5. Шамова Т. И. Управление процессом формирования системы качества знаний учащихся: Метод. пособие / Т. И. Шамова, Т. М. Давыденко. - М., 1990. - 112 с.

6. Юнина Е. А. Технология качественного обучения в школе: учеб.- метод. Пособие. - М.: Педагогическое общество России, 2007. - 224 с. 